\title{
The National Oncology PET Registry (NOPR): A monumental effort by a few leaders
}

\section{Johannes Czernin}

This current volume features 2 manuscripts by the NOPR team that may represent the final chapter of their monumental work $(1,2)$. Previous efforts by the group led by the late Ed Coleman, Barry Siegel, Bruce Hillner and Anthony Shields resulted in near universal coverage of $18 \mathrm{~F}-\mathrm{FDG}$ PET imaging in oncology $(3,4,5)$. NOPR also demonstrated that coverage with evidence development in collaboration with the Centers for Medicare \& Medicaid Services was not only feasible but provided highly relevant information for beneficiaries and health care providers. Rodney Hicks provides an invited perspective on the 2 current manuscripts.

My brief commentary is in fact a thank you note. Thank you to our late friend Ed Coleman, a true pioneer of PET imaging; to the tireless Barry Siegel who always believed that this can be done, who spent months and years to negotiate with CMS and who kept expanding NOPR as shown in the current volume of JNM; to Anthony Shields, whose insights into oncology were necessary to ask the right questions; to Bruce Hillner, whose analytical mind was instrumental for developing the right study endpoints and coming up with comprehensive irrefutable answers.

A thank you also to the Academy of Molecular Imaging (now World Molecular Imaging Society) whose leadership creatively convinced industry to fund this effort. And finally, a thank you to the team that now provided evidence for the value of $18 \mathrm{~F}-\mathrm{NaF}$ PET imaging for evaluating bone metastatic disease.

This group of leaders accomplished something that only few believed to be possible. They provided the evidence for the indisputable value of $18 \mathrm{~F}-\mathrm{FDG}$ and $18 \mathrm{~F}-\mathrm{NaF}$ imaging in oncology. We will need leaders like this to move our field forward.

Theranostic approaches targeting the Somatostatin Receptors (SSR) and the Prostate Specific Membrane Antigen (PSMA) await FDA approval and CMS reimbursement. We are now challenged to generate data of equally high quality for both diagnostics and therapeutics. That this can be done has been demonstrated so impressively by a few great leaders. 
1) Intended vs. Inferred Treatment after 18 F-Fluoride PET Performed for Evaluation of Osseous Metastatic Disease in the National Oncologic PET Registry. Hillner BE, Hanna L, Makineni R, Duan F, Shields AF, Subramaniam RM, Gareen I, Siegel BA. J Nucl Med. 2017 Nov 30. pii: jnumed.117.205047. doi: 10.2967/jnumed.117.205047.

2) Hospice Admission and Survival following 18F-Fluoride PET Performed for Evaluation of Osseous Metastatic Disease in the National Oncologic PET Registry llana Gareen, Bruce E. Hillner , Lucy Hanna, Rajesh Makineni , Fenghai Duan, Anthony F. Shields, Rathan M. Subramaniam6 , Barry A. Siegel

3) Hillner BE, Siegel BA, Liu D, et al. Impact of positron emission tomography/computed tomography and positron emission tomography (PET) alone on expected management of patients with cancer: initial results from the National Oncologic PET Registry. J Clin Oncol. 2008;26:2155-2161.

4) 4. Hillner BE, Siegel BA, Shields AF, et al. Relationship between cancer type and impact of PET and PET/CT on intended management: findings of the National Oncologic PET Registry. J Nucl Med. 2008;49:1928-1935.

5) 5. Hillner BE, Siegel BA, Shields AF, et al. The impact of positron emission tomography (PET) on expected management during cancer treatment: findings of the National Oncologic PET Registry. Cancer. 2009;115:410-418. Erratum in: Cancer. 2009;115:1133. 